\title{
Frequency of Color Vision Deficiency among Saudi Dental Students: A Cross-Sectional Study
}

\author{
Najla A. Alqahtani ${ }^{1} \quad$ Rafi A. Togoo ${ }^{1} \quad$ Mashael M. Alqahtani $^{1} \quad$ Nouf S. Suliman $^{1} \quad$ Foziah A. Alasmari $^{1}$ \\ Faris M. Alqahtani ${ }^{1} \quad$ Fahad T. Alshahrani ${ }^{1}$
}

${ }^{1}$ Department of Pediatric Dentistry and Orthodontics, King Khalid

Address for correspondence Rafi A. Togoo, BDS, MDS, Department University College of Dentistry, Abha, Kingdom of Saudi Arabia of Pediatric Dentistry and Orthodontics, King Khalid University College of Dentistry, Abha 61421, Kingdom of Saudi Arabia (e-mail: ratogo@kku.edu.sa).

\begin{abstract}
Keywords

- color vision

- dental students

- dentistry

- red-green color vision deficiency

Objective The current research was conducted to evaluate the frequency of colorvision deficiency among dental students of King Khalid University College of Dentistry, Saudi Arabia.

Materials and Methods A cross-sectional study was performed among 203 dental students working as interns at male and female dental clinics of King Khalid University College of Dentistry (KKUCOD), Saudi Arabia. The Ishihara color-vision deficiency (CVD) test with 24 plates was used for diagnosis of the problem. Analysis of the data was done by performing Chi-square tests using SPSS software version 20.

Results The frequency of total CVD was found to be $3.9 \%$. While the association of gender with total CVD was observed to be statistically nonsignificant, a statistically significant relation was drawn with red-green color deficiency. Out of the total of 203 patients, 44 males were identified with red-green color deficiency, whereas only three females were found to have this condition, therefore revealing that CVD is more prevalent in males. Age was found to have a significant association with red-green color vision deficiency, protanopia, and total CVD.

Conclusion A total of $20.19 \%$ male dental students had red-green color vision deficiency compared to $1.4 \%$ in female students. The dental students must be aware of their congenital color vision deficiency and its impact on their professional life. Screening of such dental students and professionals is quite important so that they can tackle the color vision problems well without having detrimental effect on their future dental practice.
\end{abstract}

\section{Introduction}

An adequate color vision and the ability to correctly perceive all colors is an essential variable in dentistry, especially during tooth-restoration procedures using various tooth-color shades. ${ }^{1} \mathrm{~A}$ dentist with a normal color vision can appropriately identify the individual shade variability of the teeth and accordingly provide efficient dental care. ${ }^{2}$ Color vision plays a crucial role in dentistry, as several medical conditions are identified by scrutinizing the changes in

DOI https://doi.org/ 10.1055/s-0040-1714766 ISSN 1305-7456. color, such as the changes seen in oral mucosa in different oral lesions. Color-vision deficiency (CVD) is a medical ailment where an individual is unable to differentiate colors and experience disturbances of color perception. It occurs when the amount of visual pigment per cone photoreceptors is less or when more than one cone system is absent. ${ }^{3}$ In other words, people with the absence of red, green, or blue cones in the retina find it extremely difficult to determine the difference between these colors. In a functional visual system, the three-cone photo pigment is formed due to their

(C) 2020. European Journal of Dentistry.

This is an open access article published by Thieme under the terms of the Creative Commons Attribution-NonDerivative-NonCommercial-License, permitting copying and reproduction so long as the original work is given appropriate credit. Contents may not be used for commercial purposes, or adapted, remixed, transformed or built upon. (https://creativecommons.org/licenses/by-nc-nd/4.0/)

Thieme Medical and Scientific Publishers Pvt. Ltd., A-12, 2nd Floor, Sector 2, Noida-201301 UP, India 
reaction with the light of varying wavelengths. If there exists genetic mutation affecting the expressions of these cones, CVD syndrome is recognized. CVD is most common among males compared with females with a ratio of $8: 0.5 \%{ }^{1}$ While CVD does not result in complete blindness, individuals with this condition find that it challenging to perform everyday functions as they lack an understanding of the visual world. ${ }^{4}$

Medical doctors or dentists with CVD encounter several difficulties in their practice when trying to identify the signs of diseases, thereby leading to diagnostic errors. The inability to determine clinical signs based on color and shade is disadvantageous in aesthetic restorative dentistry. ${ }^{5}$ The clinical errors made by those with CVD are higher than those with normal color vision. Dentists with red-green color vision deficiency find it challenging to determine the color due to lighting conditions and color temperature. ${ }^{6}$

Furthermore, abnormal color vision is regarded to be untreatable and nonprogressive, which is troublesome and is rendered as a grave issue in dentistry. ${ }^{4}$ Several dentists do not acknowledge the severity of this issue, and few are even unaware of their color deficiency. However, because of limited evidence, the real impact of CVD on the professional lives of dentists is unclear, especially regarding the practice of restorations. Moreover, among dental students, the undiagnosed CVD could prove to be a detriment to the performance of an affected student. Therefore, the purpose of the current study was to evaluate the frequency of CVD among dental students of King Khalid University College of Dentistry, Abha, Saudi Arabia.

\section{Materials and Methods}

The current study was cross-sectional research conducted among dental students working in clinics at the male and female campus of King Khalid University College of Dentistry. A convenient sample of 203 students and interns was selected for the study. The patients were ruled out for any vision related refractive errors. The study makes use of the Ishihara color test that is efficient for detecting color vision deficiency. The test includes 24 plates; 1 to 17 plates comprise of a number and 18 to 24 plates comprises two or more free-hand lines. The participants were made to sit approximately $75 \mathrm{~cm}$ from the monitor with each circle set at eye level with mild natural light and no glare on the screen. The participants were asked to identify the hidden number or line on each plate within 5 seconds. The inputs of the participants were noted, and were cross-checked with answers that were displayed on the screen after clicking on each plate. Chi-square tests were performed using SPSS version 19 (SPSS Inc., Chicago IL) for data analysis.

Before the conduct of the test, the examiner was calibrated for performing the CVD test. Kappa statistics was used to assess the intraobserver reliability. Kappa coefficient was found to be 0.8 (substantial). Male and female dental students and interns willing to participate in the study were included except those having medical/systemic problems and also the preclinical students were excluded from the study.

\section{Ethical Considerations}

The current study ensured that all the ethical rules are followed by taking necessary permissions from the University. Ethical approval was obtained from the Scientific Research Committee, King Khalid University College of Dentistry Abha (SRC/ETH/2018-19/099). Informed patient consent was taken from the participants before start of the study.

\section{Results}

It is understood from the analysis that total color vision deficiency was observed among $3.9 \%$ of the sample. Around $21.7 \%$ (47) of the population had a red-green deficiency, and $2 \%$ of them had protanopia, a state where the red cone is absent.

A statistically nonsignificant $(p=0.678)$ difference was found when CVD and normal vision were compared based on gender. As per the analysis, there was no statistically significant association between gender and prevalence of protanopia. Gender was found to be statistically associated with red-green color deficiency, where 41 males were found to have a red-green color deficiency, and only 3 females were diagnosed with this deficiency (-Table $\mathbf{1}$ ). The analysis revealed that gender has no statistically significant impact on the total CVD ( - Table 2).

\section{Association between Age and Color-Vision Deficiency}

As per the analysis, it is observed that age was a crucial factor that affects the overall vision of the participants. According to the study, $33.3 \%$ of the participants lying under the age group of 26 to 28 years had a lower vision. The vision is depleted

Table 1 Comparison of normal and red-green color deficiency based on gender

\begin{tabular}{|c|c|c|c|c|c|}
\hline \multicolumn{6}{|c|}{ Crosstab } \\
\hline & & & \multicolumn{2}{|c|}{ Red-green color deficiency } & \multirow[t]{2}{*}{ Total } \\
\hline & & & Normal & Present & \\
\hline \multirow[t]{4}{*}{ Gender } & \multirow[t]{2}{*}{ Male } & Count & 62 & 41 & 103 \\
\hline & & $\%$ within Gender & $60.2 \%$ & $39.8 \%$ & $100.0 \%$ \\
\hline & \multirow[t]{2}{*}{ Female } & Count & 97 & 3 & 100 \\
\hline & & $\%$ within Gender & $97.0 \%$ & $3.0 \%$ & $100.0 \%$ \\
\hline \multirow{2}{*}{\multicolumn{2}{|c|}{ Total }} & Count & 159 & 44 & 203 \\
\hline & & $\%$ within Gender & $78.3 \%$ & $21.7 \%$ & $100.0 \%$ \\
\hline
\end{tabular}

Note: statistically significant $(p=0.000)$. 
Table 2 Comparison of normal and total color-vision deficiency based on gender

\begin{tabular}{|c|c|c|c|c|c|}
\hline \multicolumn{6}{|c|}{ Crosstab } \\
\hline & & & \multicolumn{2}{|c|}{ Total color-vision deficiency } & \multirow[t]{2}{*}{ Total } \\
\hline & & & Normal & Present & \\
\hline \multirow[t]{4}{*}{ Gender } & \multirow[t]{2}{*}{ Male } & Count & 101 & 2 & 103 \\
\hline & & $\%$ within Gender & $98.1 \%$ & $1.9 \%$ & $100.0 \%$ \\
\hline & \multirow[t]{2}{*}{ Female } & Count & 94 & 6 & 100 \\
\hline & & $\%$ within Gender & $94.0 \%$ & $6.0 \%$ & $100.0 \%$ \\
\hline \multirow{2}{*}{\multicolumn{2}{|c|}{ Total }} & Count & 195 & 8 & 203 \\
\hline & & $\%$ within Gender & $96.1 \%$ & $3.9 \%$ & $100.0 \%$ \\
\hline
\end{tabular}

Note: statistically non-significant; $p=0.130$.

Table 3 Comparison of frequency distribution of color-vision deficiency and normal based on age

\begin{tabular}{|c|c|c|c|c|c|}
\hline \multicolumn{6}{|c|}{ Crosstab } \\
\hline & & & \multicolumn{2}{|c|}{ Vision } & \multirow[t]{2}{*}{ Total } \\
\hline & & & Deficient & Normal & \\
\hline \multirow[t]{6}{*}{ Age category } & \multirow[t]{2}{*}{$20-22$ years } & Count & 1 & 65 & 66 \\
\hline & & $\%$ within age category & $1.5 \%$ & $98.5 \%$ & $100.0 \%$ \\
\hline & \multirow[t]{2}{*}{$23-25$ years } & Count & 2 & 132 & 134 \\
\hline & & $\%$ within age category & $1.5 \%$ & $98.5 \%$ & $100.0 \%$ \\
\hline & \multirow[t]{2}{*}{$26-28$ years } & Count & 1 & 2 & 3 \\
\hline & & $\%$ within age category & $33.3 \%$ & $66.7 \%$ & $100.0 \%$ \\
\hline \multirow{2}{*}{\multicolumn{2}{|c|}{ Total }} & Count & 4 & 199 & 203 \\
\hline & & $\%$ within age category & $2.0 \%$ & $98.0 \%$ & $100.0 \%$ \\
\hline
\end{tabular}

Note: statistically significant; $p=0.000$.

Table 4 Comparison between normal and protanopia patients based on age

\begin{tabular}{|c|c|c|c|c|c|}
\hline \multicolumn{6}{|c|}{ Crosstab } \\
\hline & & & \multicolumn{2}{|c|}{ Protanopia } & \multirow[t]{2}{*}{ Total } \\
\hline & & & Normal vision & Protanopia & \\
\hline \multirow[t]{6}{*}{ Age category } & \multirow[t]{2}{*}{$20-22$ years } & Count & 65 & 1 & 66 \\
\hline & & $\%$ within age category & $98.5 \%$ & $1.5 \%$ & $100.0 \%$ \\
\hline & \multirow[t]{2}{*}{$23-25$ years } & Count & 132 & 2 & 134 \\
\hline & & $\%$ within age category & $98.5 \%$ & $1.5 \%$ & $100.0 \%$ \\
\hline & \multirow[t]{2}{*}{$26-28$ years } & Count & 2 & 1 & 3 \\
\hline & & $\%$ within age category & $66.7 \%$ & $33.3 \%$ & $100.0 \%$ \\
\hline \multirow{2}{*}{\multicolumn{2}{|c|}{ Total }} & Count & 199 & 4 & 203 \\
\hline & & $\%$ within age category & $98.0 \%$ & $2.0 \%$ & $100.0 \%$ \\
\hline
\end{tabular}

Note: statistically significant; $p=0.000$.

with increasing age (-Table $\mathbf{3}$ ). There is a significant association between age and prevalence of protanopia where the participants with older age were more susceptible to protanopia. The $p$-value is found to be significant ( - Table 4 ).

As per the analysis, age is found to be associated with redgreen deficiency, where participants with 23 to 25 years of age (30.6\%) and those with 26 to 28 years (33.3\%) have this deficiency. Also, $3 \%$ of participants of 20 to 22 years of age had red-green color deficiency. $p$-Value is observed to be significant (-Table 5). The analysis revealed that age has a significant impact on the total color vision deficiency. The same is reflected in - Table $\mathbf{6}$.

\section{Discussion}

The presence of CVD causes difficulties while performing clinical investigations by medical/dental professionals. ${ }^{7,8}$ In medical profession, the physicians have to come across 
Table 5 Comparison of frequency distribution of red-green deficiency and normal deficiency based on age

\begin{tabular}{|c|c|c|c|c|c|}
\hline \multicolumn{6}{|c|}{ Crosstab } \\
\hline & & & \multicolumn{2}{|c|}{ Red-green color deficiency } & \multirow[t]{2}{*}{ Total } \\
\hline & & & Normal & Present & \\
\hline \multirow[t]{6}{*}{ Age category } & \multirow[t]{2}{*}{$20-22$ years } & Count & 64 & 2 & 66 \\
\hline & & $\%$ within age category & $97.0 \%$ & $3.0 \%$ & $100.0 \%$ \\
\hline & \multirow[t]{2}{*}{$23-25$ years } & Count & 93 & 41 & 134 \\
\hline & & $\%$ within age category & $69.4 \%$ & $30.6 \%$ & $100.0 \%$ \\
\hline & \multirow[t]{2}{*}{$26-28$ years } & Count & 2 & 1 & 3 \\
\hline & & $\%$ within age category & $66.7 \%$ & $33.3 \%$ & $100.0 \%$ \\
\hline \multirow{2}{*}{\multicolumn{2}{|c|}{ Total }} & Count & 159 & 44 & 203 \\
\hline & & $\%$ within age category & $78.3 \%$ & $21.7 \%$ & $100.0 \%$ \\
\hline
\end{tabular}

Note: statistically significant; $p=0.000$.

Table 6 Age versus total color vision deficiency

\begin{tabular}{|c|c|c|c|c|c|}
\hline \multicolumn{6}{|c|}{ Crosstab } \\
\hline & & & \multicolumn{2}{|c|}{ Total color-vision deficiency } & \multirow[t]{2}{*}{ Total } \\
\hline & & & Normal & Present & \\
\hline \multirow[t]{6}{*}{ Age category } & \multirow[t]{2}{*}{$20-22$ years } & Count & 63 & 3 & 66 \\
\hline & & $\%$ within age category & $95.5 \%$ & $4.5 \%$ & $100.0 \%$ \\
\hline & \multirow[t]{2}{*}{$23-25$ years } & Count & 130 & 4 & 134 \\
\hline & & $\%$ within age category & $97.0 \%$ & $3.0 \%$ & $100.0 \%$ \\
\hline & \multirow[t]{2}{*}{$26-28$ years } & Count & 2 & 1 & 3 \\
\hline & & $\%$ within age category & $66.7 \%$ & $33.3 \%$ & $100.0 \%$ \\
\hline \multirow{2}{*}{\multicolumn{2}{|c|}{ Total }} & Count & 195 & 8 & 203 \\
\hline & & $\%$ within age category & $96.1 \%$ & $3.9 \%$ & $100.0 \%$ \\
\hline
\end{tabular}

Note: statistically significant $(p=0.027)$.

the patients having conditions, such as cyanosis, jaundice, hematuria or hematochezia, for which the changes in color is to be observed keenly and with efficiency by the health professionals for the appropriate diagnosis and treatment of such diseases. ${ }^{9}$ For dental professionals, oral mucosa, tongue, gingiva, palate are essential parameters to denote color change to be monitored and examined in various oral mucosal lesions such as leukoplakia, oral lichen planus, and erythroplakia. Moreover, the shade-matching and selection during prosthesis and esthetic restorative procedures are also dependent on color vision among dentists. Even though colorimetric instrumentation is used in modern dental practice, still the final shade-match approval is dependent on the human observer. ${ }^{10}$ In yet another previously conducted research, it was observed by Davison and Myslinski ${ }^{11}$ that a significantly higher number of errors in matching hue and chroma depicting the color and saturation of teeth was made by dentists suffering from CVD when compared with those with normal color vision.

The Ishihara test for CVD and American Optical Company Hardy-Rand-Ritter (AOH-R-R) test are commonly used reliable color vision tests wherein pseudoisochromatic plates are used to detect the CVD of an individual. ${ }^{12}$ The current study has utilized the Ishihara-24 plates color deficiency test for diagnosis of the color-vision related problems of the participants.

It was inferred from the current study that the prevalence of total CVD among study participants was 3.9\%. A study by Khalid et $\mathrm{al}^{1}$ also found a frequency of $3.75 \%$ CVD among dental students depicting similar results to that of the present study. Out of the total participants, $21.7 \%$ were diagnosed with red-green CVD, while $1.97 \%$ had protanopia. Gender was found to have a statistically significant relation with red-green color vision deficiency; however, it was nonsignificantly related to the total CVD. As compared with the literature review, Khairoalsindi et $\mathrm{al}^{13}$ studied the extent and factors affecting CVD among health science students wherein the researchers used survey method and deployed 24-plate Ishihara's test of color vision chart among 1,126 students. It was observed that males experience a higher prevalence of CVD as compared with females. While two students had Tritan CVD (blue-yellow color blindness), 18 had Duran CVD (reduced sensitivity to green light). Several of the students who were diagnosed with CVD were not aware of having this defect. CVD was also revealed to be affected due to family history, where students who had family members with this deficiency were more susceptible to CVD. While the current study did not consider the factor of family history, gender 
was a considered factor, which, however, as opposed to the study by Khairoalsindi et al, ${ }^{13}$ had no significant association with total CVD. Our results were similar to that of a study by Khalid et al, ${ }^{1}$ who found no significant association between gender and CVD. The current study, however, found a statistically significant difference between male and female subjects with red-green color vision deficiency. This revelation is in alignment with the study by Siddiqui et $a l,{ }^{14}$ wherein the prevalence of red-green color vision deficiency in medical and dental students was studied. They compared the results with the CVD identified among nonmedical students. Ishihara's color vision charts were adopted to test the deficiency among 926 medical and dental students. The study found that the prevalence of the red-green CVD was 2.75\%; however, no relevant difference was observed between the prevalence of CVD among medical students and nonmedical students. CVD was also found to be more in males than females. This is also similar to the current analysis, where males were found to have a higher prevalence of red-green color vision deficiency when compared with females. Males are mostly affected while females are carriers for a color-vision abnormality as the defect is an X-linked recessive trait. ${ }^{15}$

Along similar lines, Alharfi et $\mathrm{al}^{16}$ examined red-green color deficiency among medical students by using Ishihara's charts. But $2.7 \%$ of deficiency was encountered where both females and males were observed to have CVD, although the prevalence was slightly higher among males. Woldeamanuel and Geta used Ishihara's pseudo isochromatic test 38 plates and also conducted interviews with students to evaluate their color vision. The results confirmed that there was a prevalence of $4.1 \% \mathrm{CVD}$, where males had a higher count. Most of the students detected with CVD were unaware of this condition and most were identified with deutan defects. ${ }^{17}$

As per the analysis of the current study, the vision of the participant was normal and had no association with CVD as the students with CVD were observed to have proper vision. However, as opposed to this result, Alharfi et $\mathrm{al}^{16}$ found that few of those having diagnosed with CVD also had other vision-related problems. Few of them also had a history of CVD disorder among their families, but the majority had no such issue. Therefore, no conclusions can be drawn with the relationship between family history of CVD and the prevalence of CVD. With similar results, Chandler et $\mathrm{al}^{18}$ also observed from their study that color blindness or CVD is not related to the vision of the patient, which might be the reason that the individuals having CVD mostly remain unaware about it. This matches the present study findings, wherein the patients were not known about their deficiency related to color vision. Chakrabarti ${ }^{19}$ determined that CVD is a common issue affecting the daily activities of such individuals. Problems in learning, education, and work performance may arise due to CVD. Doctors in different fields are observed to report cases of difficulties with everyday tasks and training in medicine. The researchers found that factors, such as the severity of CVD, awareness level of doctors, and personal characteristics, affect the impact of CVD on an individual. To help them cope with this disorder, it is essential to have early detection and providing support.
The current study observed a significant impact of age on vision, red-green CVD, protanopia, and total CVD. As determined by Vodanović et $a l,{ }^{20}$ vision is primarily affected by age and is a normal phenomenon. The current study found that age is significantly related to CVD, as students with 26 to 28 years of age had a higher frequency of CVD. When compared with the literature review, Nilawar et $\mathrm{l}^{21}$ observed that dental professionals between the age group of 27 to 31 years had a higher rate of CVD as compared with others. This is in alignment with the results of the present study. Pramanik et $\mathrm{a}^{22}$ also observed that age has an impact on the occurrence of CVD. Chan et a ${ }^{23}$ determined that CVD can be developed as per the increase in age. As determined by Khodadadi and Sadaghi, ${ }^{24} \mathrm{CVD}$ is a relatively common issue that is impacted by gender and age. Considering this, it is essential to have early screening processes in place for detection.

\section{Recommendations}

Screening of dental students, dentists, and dental professionals is recommended for CVDs, so that they are aware of their problem and hence overcome the same by adopting alternative ways to avoid any errors while working on the patients. For shade matching, the dental students having CVD should get training with the tooth-guide trainer. It would enable them to work with reasonable confidence and to gain patient satisfaction regarding the treatment. If the color deficiency would be detected at an early stage of students' life, then they would accordingly choose their career in the future.

\section{Areas of Future Research}

Future research should take into consideration the elated factors such as family history while studying CVD. Larger sample size may be considered to increase the external validity of the study.

\section{Conclusion}

It was inferred from the current study that total color vision deficiency was observed among $3.9 \%$ of the sample. Around $21.7 \%$ (47) of the population had a red-green deficiency, and $2 \%$ of them had protanopia. When evaluating the impact of gender and age on CVD, the study found an insignificant association between gender and CVD, but a conclusive significant relation between age and CVD. It is essential to note that as CVD can affect the performances of dentists in the future, they must be aware of this deficiency and must be screened to identify it.

\section{Funding}

None.

\section{Conflict of Interest}

None declared.

\section{References}

1 Khalid M, Chughtai MA, Mian HI, Shah SN. Frequency of colour vision deficiency among dental students. Pak Oral Dent J 2017;37(1):161-163 
2 Gokce HS, Piskin B, Ceyhan D, Gokce SM, Arisan V. Shade matching performance of normal and color vision-deficient dental professionals with standard daylight and tungsten illuminants. J Prosthet Dent 2010;103(3):139-147

3 Dohvoma VA, Ebana Mvogo SR, Kagmeni G, Emini NR, Epee E, Mvogo CE. Color vision deficiency among biomedical students: a cross-sectional study. Clin Ophthalmol 2018;12:1121-1124

4 Goh SS, Chan VXB, Tan NC. Colour vision deficiency: is it a handicap? A narrative review of its impact on medical \& dental education and practice. Proceedings of Singapore Healthcare 2014;23(2):149-157

5 Khosla A, Maini AP, Wangoo A, Singh S, Mehar DK. Prevalence of Colour Vision Anomalies Amongst Dental Professionals and its Effect on Shade Matching of Teeth. J Clin Diagn Res 2017;11(1):ZC33-ZC36

6 Chaudhari SV, Chaudhari PS, Patel R, Shete R. A Survey on Colorblindness in Pharmacy Students at Wagholi, Pune. Int J Innov Res Dev 2013;2(3):518-524

7 Ali L. Color vision deficiency (CVD) in the medical and allied occupations. J Univ Med Dent Coll 2012;3(1):1-5

8 Spalding JA. Medical students and congenital colour vision deficiency: unnoticed problems and the case for screening. Occup Med (Lond) 1999;49(4):247-252

9 Spalding JAB. Doctors with Daltonism and the implications for counselling. Optometry Today 2002;42:23-25

10 Ragain JC. A Review of Color Science in Dentistry: The Process of Color Vision. J Dent Oral Disord Ther 2015;3(1):1-4

11 Davison SP, Myslinski NR. Shade selection by color vision-defective dental personnel. J Prosthet Dent 1990;63(1):97-101

12 Nolte J, The Human Brain: An Introduction to Its Functional Anatomy. 6th ed. St. Louis: Mosby Vital Book file; 2009

13 Khairoalsindi OA, Almasoudi BM, Bamahfouz AY, Alghamdi AA, Siddiqui MI. Prevalence and determinants of colour vision defects among preparatory university students at Makkah, Saudi Arabia. Middle East Afr J Ophthalmol 2019;26(3):133-137
14 Siddiqui QA, Shaikh SA, Qureshi TZ, Subhan MM. A comparison of red-green color vision deficiency between medical and non-medical students in Pakistan. Saudi Med J 2010;31(8):895-899

15 Guyton AC, Hall JE, Textbook of Medical Physiology, 11th ed. Philadelphia, Pennsylvania: Elsevier Publication; 2005: 633

16 Alharfi SM, Al-Braheem GM, Al-Khamis FA, et al. Prevalence of color vision deficiency among medical students in KFU-SA (2014-2015) Int J Sci Res (Ahmedabad) 2016;5(6):53-56

17 Woldeamanuel GG, Geta TG. Prevalence of colour vision deficiency among school children in Wolkite, Southern Ethiopia. BMC Res Notes 2018;11(1):838

18 Chandler NP, Gray AR, Murray CM. Eyesight: a study of the staff of a dental school. BDJ Open 2017;3(1):17008

19 Chakrabarti S. Psychosocial aspects of colour vision deficiency: implications for a career in medicine. Natl Med J India 2018;31(2):86-96

20 Vodanović M, Sović S, Galić I. Occupational health problems among dentists in Croatia. Acta Stomatol Croat 2016;50(4):310-320

21 Nilawar S, Budhiraja S, Waghmare R, Katekhaye S, Khandelwal R. Prevalence of color blindness in dental professionals: a survey. Journal of Interdisciplinary Dental Sciences 2019;8(1):6-9

22 Pramanik T, Khatiwada B, Pandit R. Color vision deficiency among a group of students of health sciences. Nepal Med Coll J 2012;14(4):334-336

23 Chan XBV, Goh SM, Tan NC. Subjects with colour vision deficiency in the community: what do primary care physicians need to know? Asia Pac Fam Med 2014;13(1):1-10

24 Khodadadi R, Sadaghi MA. Frequency of color vision disorder among undergraduate and post-graduate students in Isfahan faculty of dentistry. Journal of Isfahan Dental School 2011;6(5):853-858 